Tom Burns

\title{
Introduction
}

In 1995, the Northern Territory of Australia became the first jurisdiction in the world to enact a statute law which allowed access to voluntary euthanasia. The Territory was subsequently overruled by the Commonwealth, and since then many legislators have proposed bills similar to that which was passed in 1995 or bills which would undo the overruling. To date, no such bills ${ }^{1}$ have successfully navigated their respective parliaments - but should they have?

Given that none of us could reasonably wish for people to die or suffer without necessity, both proponents and opponents of the legalisation of voluntary euthanasia must be capable of justifying the impact of legalisation or criminalisation of voluntary euthanasia ${ }^{2}$. As such, we cannot simply say that all forms of legalisation or criminalisation are justifiable or unjustifiable without first examining the salient features of a given proposal. Unfettered, on-demand access to voluntary euthanasia for any and all - be they competent and informed at the time of request and/or death or not - is not clearly ethical if we wish to avoid unnecessary deaths. Equally, complete restriction - no matter the unbearableness of someone's pain - is also not clearly ethical if we wish to avoid unnecessary suffering. Thus, of the 29 bills presented to Australian parliaments that sought to legalise access, not all may have been ethical simply because the reason that they sought to legalise access; to say one way or the other, they must be examined on their individual merits.

However, to examine each of these 29 bills section-by-section, line-by-line would be too onerous a task (both for the reader and the author), and would risk obscuring the aim of this project

\footnotetext{
${ }^{1}$ A list of bills proposed in Australian parliaments are listed in Appendix I.

2 'Voluntary Euthanasia and the Risk of Abuse' in The Least Worst Death, Margaret Battin. Oxford University Press, 1994, p. 165.
} 
in too many technical and less important details. Instead, I will identify and discuss major similarities among the bills and select two major issues to discuss at greater length. This approach has the advantage of allowing enough space to be philosophically interesting while remaining empirically relevant.

\section{Laying the foundation}

Before delving into this greater task, it is necessary to lay the basic foundation on which all of these proposals lie upon. Two principles the bills all implicitly accept are that certain cases of euthanasia can be ethically justifiable, and that the state should concern itself with medical practice, including the practice of euthanasia. These fundamental bases for euthanasia legislation seem to be well-supported by the majority of the Australian public ${ }^{3}$, however in the interest of completeness, I will briefly defend these two principles here.

First, that certain cases of euthanasia can be ethical: It needn't matter whether the exemplar is theoretical or actual, however if a given case can be said to have been ethical, then we can say that future cases of a similar nature would also be ethical. For the sake of relevance I will present the actual Australian case of Bob Dent, the first person to make use of the Territory's Rights of the Terminally III Act 1995. If we stick by our initial values of wishing to avoid unnecessary death and suffering, for Mr Dent's decision to be ethical, I will now demonstrate that we must (at least) be convinced that his decision avoided unnecessary suffering and that death was necessary to alleviate this suffering. Anything less would be in violation of our initial values.

Mr Dent's decision to request euthanasia was after a five year battle with prostate cancer, which, in his final months, he described as "a roller-coaster of pain made worse by the unwanted

\footnotetext{
${ }^{3}$ 'Our parliament must respect public opinion on a right to die for the terminally ill' Ross Fitzgerald. The Australian. 13 September 2014.
} 
side effects of the [palliative] drugs. ${ }^{14} \mathrm{He}$ had endured countless surgeries and attempts to rid his body of the cancer, but his condition had become terminal ${ }^{5}$ - further treatment would be futile, experimental, and/or could easily result in more or worse suffering without any benefit. His debilitating illness and constellation of symptoms lead him to make the conscious choice to relieve his suffering by the ultimate means, but by the only means left that could - in his view - fully alleviate (and be guaranteed to alleviate) his suffering, which it did on 22 September $1996^{6}$. A combination of barbiturates and a muscle relaxant administered by a computerised syringe under the control of $\mathrm{Mr}$ Dent $^{7}$ affected his peaceful death within minutes of him confirming his wishes. Before this, a long process of confirming his condition, mental state, and personal decision was conducted. A physician specialising in Mr Dent's condition confirmed his diagnosis and prognosis, a leading psychiatrist from Sydney confirmed he was not suffering from treatable mental illness, and Mr Dent had had time to carefully think about his decision during a cooling off period of nine days ${ }^{8}$. Throughout this entire process, his general practitioner, Philip Nitschke, made himself available to Mr Dent to guide him through the process and counsel him on his medical options. Dr Nitschke also supervised Mr Dent's death and set-up the computerised syringe ${ }^{9}$. It cannot be said, then, that Mr Dent lacked medical information, mental competence, psychological counselling, alternative medical options, or

\footnotetext{
4 'Why I need to die' Bob Dent. The Sydney Morning Herald. 27 September 1996.

5 'Bob Dent's Decision' Helga Kuhse, Peter Singer. Bioethics, 1997, v. 11 (1), p. iii.

${ }^{6}$ 'Death - whose decision? Euthanasia and the terminally ill' Journal of Medical Ethics. 2000, v. 26, p. 121.

${ }^{7}$ Although it could be rightly argued that the Rights of the Terminally III Act 1995 permitted physician-assisted suicide, not euthanasia, I do not suppose here that there is an significant ethical difference between the two. Although there could indeed be cases which make these differences ethically significant, this essay attempts to deal with patients' overall access to end-of-life choices (including euthanasia and assisted suicide), not their precise means of their own wishes being enacted.

8 Ibid 5.

${ }^{9}$ Ibid 5.
} 
opportunity (at any time) for reconsideration. He made an autonomous choice. Further, the alternative medical options available to him would not have alleviated his suffering to an extent that was satisfactory to him.

It is important at this point to distinguish suffering from physical pain - the two are not equivalent. Some people can enjoy pain. Muscle soreness after exercise might be physically painful but the person experiencing that pain might not be suffering per se because it was self-inflicted for the greater purpose and pleasure of exercise and health. Thus, even if Mr Dent's physical pain could have been stably, pharmacologically alleviated (which, as it happened, was not possible), he might still have suffered, perhaps in a psychological or existential sense which was untreatable except for by death. By psychological and existential suffering, we mean suffering that falls outside of the general or normal realm of clinical medicine in source, but not necessarily suffering that can't be alleviated by clinical medicine in method. For example, Mr Dent might have suffered from a rational fear of his future wellbeing or from a loss of autonomy and sense of dignity or meaning in his life. Such suffering might not show up in a blood test or be diagnosable via a x-ray, but such suffering does exist, and affects people greatly ${ }^{10}$, especially when they are nearing the end of their natural life. While these types of suffering, unrelated to physical pain, might be more difficult for a medical doctor to diagnose or make treatment decisions upon, we shouldn't ignore their existence or our ability to heal such suffering using medical means. In this case, Mr Dent's suffering - from both physical pain and non-physical-pain sources - would have been experienced unnecessarily or needlessly (according to Mr Dent's determination of what he found tolerable and necessary for him to enjoy his life or to 'live') and so he found that death, in his case, was necessary to avoid this suffering. That is not to say that all who found themselves in a position similar to Mr Dent's are obligated to make a similar determination, only that if they find their suffering to be intolerable to the extent that it is unnecessary for them to suffer it (as determined by them), then their choice to

\footnotetext{
10 'The Nature of Suffering and the Goals of Medicine' Eric Cassell. Oxford University Press, 1991, p. 28
} 
die (to mitigate this suffering) adheres to our initial principles of wishing to avoid unnecessary death and suffering. However, these principles need not prevent individuals from continuing to live with extreme, or what others consider unbearable or unnecessary, suffering, as individuals might find that any amount of suffering is tolerable (or not unnecessary) in order to continuing living in whatever capacity they are able to. Additionally, these are not the only relevant principles we ought to observe for all cases; we can imagine other relevant principles in theoretical iterations of $\mathrm{Mr}$ Dent's case. For example, if he had promised his family to stay with them until an important personal or cultural event had been celebrated (perhaps Christmas or a birthday), we might say that Mr Dent's decision to die before then wasn't as good as if he had honoured his promise (assuming there wasn't another competing factor to warrant otherwise, such as a serious and sudden worsening of his symptoms).

The only sizeable, remaining ethical problem we might have with Mr Dent's decision is the suggestion that he devalued his own life - or an objection stemming from the 'sanctity of life' argument. A version of this argument could hold that "every person has inherent dignity that should be recognised and respected in any condition of health, infirmity or disability"11, and that by being euthanised, Mr Dent failed to recognise his life's inherent dignity. Such an argument fails, however, when faced by two simple counter-objections: (1) that the dignity, value, or sanctity of Mr Dent's life had already been taken by his illness, and (2) that ultimately, since only Mr Dent could genuinely evaluate what dignity, value, or sanctity his life had, Mr Dent's autonomous decision ought to be respected as being true in the sense of it having the dignity, value, or sanctity he determined it to have. If his decision was not autonomous (if he was not mentally competent, for instance), then we as outsiders - could attempt to make such a determination on his behalf. In any other circumstance, if a person is mentally competent and can otherwise make an autonomous determination and

\footnotetext{
${ }^{11}$ 'Why Should the Baby Die?' Joseph Tham. Hong Kong Journal of Paediatrics, 2012, v. 17, p. 265.
} 
decision, this must supersede an outsider's belief about that person's life's dignity, value, or sanctity, since an outsider cannot have more information about the person than the person themselves.

That said, we cannot rule out such a decision, even one autonomously made, as being misaligned with a patient's best interests. To insist otherwise would be to say that no autonomous decision can ever be mistaken in the sense that its results were not in the best interests of the person who made the decision. Although we could seek to broaden our definition of autonomy to include only what results in our best interests, this would effectively be creating such a high standard of 'true autonomy' as to remain almost completely impracticable. For, to know what is in our best interests, we might have know not only everything that is possible to know about a decision's context or its future ramifications, but also how our decision will affect our interests. We must additionally know what our interests definitely are and what they will be in the future. I might autonomously choose to watch a particularly horrific film, but this experience may not be in my best interests if I then had difficulty sleeping peacefully or became irrationally scared of scenarios which I needed to navigate in my everyday life. In the case of someone wishing to be euthanised, it might not then have been in that person's interests to meet their grandchildren because their grandchildren did not then exist or there was no reason at that time to think they would exist. Similarly, perhaps someone could make an autonomous decision to be euthanised but not then realise how much a current relationship or feature of their life means to them. So, since perfect knowledge of the future and of our own best interests is not always possible, we must admit that not all autonomous decisions may be in our best interests. Nevertheless, could you or I reliably stop or somehow intervene in such situations to an extent that we are able to save a person from making an autonomous decision (to access or not access, say, euthanasia) that happened to not be in their best interests? While it might be possible - in principle - to identify a few of these cases, and to even successfully intervene in them, to do so reliably would be just as impossible as it would be for the persons making such incorrect decisions to reliably realise their mistakes with regards to their determination of their own values, their prediction of the future, or in whatever other way they 
have unfortunately failed to make a decision that would have otherwise been in their best interests. Therefore, that we, as autonomous agents, can be victims to our own autonomous decisions due to the inherent imperfections of our human capacity to imagine the future, perfectly know our interest, etc., is not reason enough to lean towards any one choice over another by default in any decision important ones especially. Since all choices will have this risk (with respect to being prone to not being in our best interests), and possibly all to the same level, it might be just as possible for an autonomous agent to be mistaken about their decision to live as it is for another's decision to die. Both mistakes would lead to either unnecessary suffering or unnecessary death, but as these mistakes cannot be reliably avoided, making either choice the default or only option is arbitrary. However, since we would ideally prefer for these mistakes not to be made at all, we can still seek to ensure that in as many cases as possible the patient has as the time and information, that is reasonable and available to them, to help confirm that such mistakes aren't made. We can also attempt to have others confirm the patient's best interests and counsel the patient in their decisionmaking process ${ }^{12}$.

Mr Dent's determination of his best interests and his decision to die based upon this determination was therefore not necessarily any more right or wrong than any others' determinations to use (die) or not utilise the Act. This is despite all of these people being fully autonomous. However, we can attempt to look at other hypothetical reasons for us to question the morality of Mr Dent's decision, which we can only do after knowing more about his specific case - for instance, if we knew that he had made a promise to his family to stay with them until a certain time. Having this level of knowledge for all potential euthanasia cases, however, is legislatively and juridically impracticable. After all, could we say that all cases which met the criteria for the Territory's legislation would have been ethical without first examining them in detail? No, this would

\footnotetext{
${ }^{12}$ Counselling not in the sense of advocating for any particular choice, but counselling in the sense of helping the patient realise their own values and best interests, whatever they happen to be.
} 
be naïve; some may have unjustly broken a promise to their family to stay with them until Christmas, or in some other way acted immorally. But just as someone's decision to divorce another might be out of spite or greed or some other immoral motive, we cannot feasibly wish to prevent all such cases. In fact, nor may we generally wish to attempt to prevent such cases, given how we may, in the process of our attempts, negatively affect genuine cases based on purer motives. As such, we cannot rule out the abuse of even the very best legislation that would legalise euthanasia ${ }^{13}$. However, just as this fact does not stop us from legalising the practice of divorce, it cannot stop us from justifying the practice of euthanasia if we determine that in the vast majority of cases the given legislation would apply to would be ethical. We must therefore be careful to define under what general conditions a person can access euthanasia in order to ensure that, generally, in those conditions, euthanasia would be an ethical option. This then leads us to the question of what ethically important details we could hope to know about the majority of cases, which we will addressed later.

The first foundational assumption of these bills, that some cases of euthanasia can be ethical, is therefore justified. The second is that the state ought to concern itself with medical practice, including the practice of euthanasia. Per our initial principles, we can quickly spot how this is also justified. Without medical practice, unnecessary suffering and death would take place. Due to the capacities of medical practice to permanently and seriously affect a person's wellbeing and to infringe upon or respect their legal rights (like the right not be unduly harmed), if the state wishes to ensure their citizens' rights and wellbeing, then the state must seek to regulate medical practice. The regulation of palliative care, including various end-of-life options like euthanasia, is therefore fully within the realm of the state's obligations to its citizens. Therefore, the state not only has the right but also the obligation to concern itself with the ethical practice of euthanasia. Now we may turn to more substantive tasks of identifying ethical issues of interest or particular note within proposed

\footnotetext{
${ }^{13}$ Ibid 2: p. 167.
} 
euthanasia laws in Australia or their associated debate. Such issues, as we will find, also appear in other forums of debate on the ethics of euthanasia legalisation around the world.

\section{Features and trends of Australian proposals}

Mr Dent's case has already alerted us to issues of effectiveness of the legislation his case (and others) was legally subject to, and such effectiveness issues have frequently been the focal point of debate in Australian parliaments. Ultimately, the question is whether the state can create effective laws applicable to the majority of euthanasia cases for which it intends to legislate on. Another frequent area of concern is whether eligibility requirements are reasonable or if they are too open or restrictive. A different concern is whether safeguards are comprehensive enough to avoid general or widespread abuses ${ }^{14}$ while simultaneously not overburdening genuine cases with too many hoops to jump through. A final area of concern, and one which was not addressed by initial proposals in Australia, is over appropriate, ongoing oversight and how or if the state ought to respond to controversial cases. Over the past twenty years, Australian parliaments have attempted to address these concerns, and in doing so have revealed some common areas of contention, advances in ethical thinking, and potential ethical problem areas. I will now highlight some ethically salient features of this history, bearing mind that our final aim is to determine which (if any) euthanasia proposals presented to Australian parliaments should have become, or remained, law.

When the Rights of the Terminally III Bill 1995 was presented in the Legislative Assembly of the Northern Territory by Country Liberal Party member and Chief Minister Marshall Perron and was passed, the main focus of its debate centred around eligibility requirements and safeguards. Patients needed to be an adult, competent at the time their wishes were expressed and carried out, diagnosed with a terminal illness, and suffering as a result of that illness. At least two doctors must have reviewed the patient's case and supported the request for euthanasia, and a psychiatrist must

\footnotetext{
${ }^{14}$ 'Seven deaths in Darwin: case studies under the Rights of the Terminally III Act, Northern Territory, Australia' David Kissane, Annette Street, and Phillip Nitschke. The Lancet, 1998, v. 352 (9134), p. 1102.
} 
have assessed the patient and found them to not be suffering from treatable mental illness. The patient needed to be fully informed throughout the entire process and a cooling-off period was mandated. These basic conditions were mostly adopted in subsequent proposals with two exceptions and two additions.

The first exception, and which became present in the large majority of proposals thereafter, was that patients would not be required to be competent at the time their wishes were carried out providing that they were competent while the safeguards and cooling-off period were satisfied. This was a notable feature of the Voluntary Euthanasia Bill 1997 presented in the Legislative Council of Western Australia by Democrats member Norm Kelly. Section 10 read as follows: "Where [a patient] becomes mentally incompetent, whether permanently or episodically, after making a request - (a) but before [safeguards, including the mandated cooling-off period,] have been completed, the request lapses; (b) and the [safeguards, including the mandated cooling-off period,] have been completed, the request has effect."

The second exception and first addition was presented in a single bill, the Dignity in Dying Bill 2002, presented in the Legislative Council of South Australia by Democrats member Sandra Kanck (and substantially contributed to by independent member Bob Such from the House of Assembly). The exception was that the patient need not be terminally ill, only "hopelessly ill", defined as such: "a person is hopelessly ill if the person has an injury or illness - (a) that will result, or has resulted, in serious mental impairment or permanent deprivation of consciousness; or (b) that seriously and irreversibly impairs the person's quality of life so that life has become intolerable to that person and there is no realistic chance of clinical improvement". The addition was in the form of oversight, and was substantial. The bill established the role of a registrar, who would maintain a register of all voluntary euthanasia requests and their status (active or revoked), and who could also conduct inquiries to determine the veracity of information recorded or to be recorded in the register. A monitoring committee comprised of medical and legal professionals, lay people, and a minister of 
religion, was required to monitor and review the operation and administration of the proposed Act, and report to the responsible government minister. This minister was also required to make an annual report to Parliament on the operation and administration of the proposed Act.

The second major addition was that of requiring the patient be a resident of the jurisdiction the bill was passed in. The first (and so far only) proposal made in the Victorian Parliament was also the first in Australia to include this eligibility requirement in the Medical Treatment (Physician Assisted Dying) Bill 2008, presented by Greens member Colleen Hartland in the Legislative Council. The motivation behind this addition was to avoid 'suicide tourism', like practices in parts of Switzerland have been branded ${ }^{15}$. The Territory's lawmakers also considered including such a requirement in 1995, however ultimately decided not to pursue this requirement. Then Health Services Minister Fred Finch stated during parliamentary debate that "legal advice has been received from the Solicitor for the Northern Territory that it may be unconstitutional to deny residents from other states access to the legislation"1617.

Together, these exceptions and additions to the initial requirements set out in the 1995 Act passed in the Northern Territory have highlighted one general and two specific developments in ethical thinking by lawmakers. The general, overarching trend towards greater complexity and length of the bills is evident by word and section count alone - the bill passed in 1995 had less than 4,000 words across 20 sections, whereas the most recent proposal made in Tasmania, the Voluntary Assisted Dying Bill 2013, had over 8,000 words across 37 sections. This increasing complexity demonstrates that, as the national discourse has progressed, political proponents have become more sophisticated in their ethical thinking, likely in part as a response to objections raised by

\footnotetext{
${ }^{15}$ 'Switzerland: Zurich votes to keep assisted suicide' British Broadcasting Corporation. 15 May 2011.

${ }^{16}$ Northern Territory Seventh Assembly First Session 21 May 1996 Parliamentary Record No. 22 p. 7657.

${ }^{17}$ Despite several calls to the office of the Solicitor for the Northern Territory, I have been unable to determine for what reasons it was advised or in what way this was advised to be possibly unconstitutional.
} 
political opponents. That this has brought about the development of oversight measures and a rich debate on eligibility requirements is credit to the democratic process (even if the majority of politicians have historically ignored the overwhelming public support - eighty-five per cent ${ }^{18}$ - that the Australian public have for legalising voluntary euthanasia for the terminally ill). This is also a reflection of the two specific developments in ethical thinking, namely the consideration of appropriate oversight measures (which were not present in bills until the early 2000s) and the increasing diversity of opinion on eligibility requirements, including if patients need to be residents of a particular jurisdiction or if they must have a terminal illness.

These specific developments in ethical thinking could be the sole subjects of essays in their own rights, and have been sufficiently interesting and complex to engage social and political commentators in years past, as well as many moral philosophers. However in the interests of space and remaining philosophically interesting, and as mentioned at the outset, this essay will focus on only two issues collectively raised by Australian proposals for euthanasia legalisation. Since oversight measures have been historically less controversial than eligibility requirements, the two selected issues relate solely to eligibility requirements. The first issue, whether patients need be terminally ill, has been presented in a number of proposals, however the second, whether patients need be an adult, has thus far been neglected by Australian parliaments (all proposals to date have required patients to be adults, and occasionally aged over 21 years).

\section{Terminal illness requirements}

Was Mr Dent terminally ill? It depends on how we wish to define the term. Legally, to access euthanasia in the way he did, he needed to be terminally ill as defined by the Territory's 1995 Act: he needed to have "an illness which, in reasonable medical judgment will, in the normal course, without the application of extraordinary measures or of treatment unacceptable to the patient, result in the

\footnotetext{
${ }^{18}$ 'Our parliament must respect public opinion on a right to die for the terminally ill' Ross Fitzgerald. The Australian. 13 September 2014.
} 
death of the patient." On a literal reading, this could be interpreted to include someone who would die as a result of refusing treatment on the grounds that it was unacceptable to them, even if their illness was a simple infection and the treatment was an antibiotic. The difficulty would be for such a patient to convince their medical doctors (especially a psychiatrist) that the treatment was so unacceptable to them that they would rather die, and that this was not an elaborate means of suicide motivated by mental illness. Although it is difficult to imagine such a scenario, it is within the realm of possibility; some patients refuse blood transfusions on the basis of their religious beliefs, and can also subsequently die. However, are these patients acting on rational beliefs? No, and "[w]e do not respect autonomy when we encourage people to act on irrational beliefs. Rather, such beliefs limit a person's autonomy. ${ }^{19}$ We needn't go so far as enforcing what we perceive to be the rational decision ${ }^{20}$, since this can be more open to question, but we should insist on rational beliefs being used as the basis for decision-making as this is less open to question. Whether it is rational to believe that the food you have been served at a restaurant has been poisoned or not is far easier to resolve than the question of whether it is reasonable to then eat the food. The former question hinges more or less on demonstrable particulars about the world we live in and how likely these are to be true, whereas the second question relies much more heavily on our personal values. If we wished to die, for instance, it would be entirely rational to eat the poisoned food, but if we believed the food was poisoned without good reason for thinking so, it is much harder to say we are being rational. Similarly, if someone would rather die than be treated with a life-saving blood transfusion or an antibiotic, it is difficult to say they are acting rationally without further explanation. Therefore, to avoid such irrationally-based decisions to be euthanised, if we wish to restrict euthanasia only to those who are terminally ill (as conceived in the common parlance), then we should redefine terminal illness to something like: "an illness which, in reasonable medical judgment will, in the

\footnotetext{
19 'Should informed consent be based on rational beliefs?' Julian Savulescu and Richard W Momeyer. Journal of Medical Ethics. 1997 (23) p. 287.

${ }^{20}$ Ibid. p. 282.
} 
normal course, without the application of extraordinary measures or of treatment unacceptable to $a$ reasonable patient, result in the death of the patient." This is closer to how we commonly conceive of terminal illness, since it would avoid cases where an irrational, unreasonable patient who, because of "ignorance, not caring enough about rational deliberation, [or] making mistakes in deliberation"21, is unable to make a fully autonomous choice, leading to their inappropriate legal status as 'terminally ill'.

If this definition was adopted, a further question arises: how far should a patient progress in their treatment before it is reasonable for them to stop? Reasonable people will surely disagree on this point, depending on their set of circumstances, tolerance for pain, personal values, and a multitude of other factors (some may even say that others' factors are non-factors and vice-versa). A reasonable person standard is not as difficult to maintain in the context of informed consent, as this standard may be tested in the courts on a case-by-case basis when the need arises ${ }^{22}$. However, unless we wish to legislate individual, case-by-case review of all requests for euthanasia to determine (for each one) whether they are 'reasonable', we could easily cause unnecessary delay and suffering for many patients. Further, it would be asking that patients first demonstrate their reasonableness before they can be granted access to their requested treatment, a requirement we do not require for the opposite treatment (receiving palliative care) or generally for treatments which have a high chance of mortality or morbidity or suffering. It also assumes that the medical staff involved can make no accurate determination about the reasonableness of the patient's decision or of their own reasonableness in supporting the patient's request.

To avoid such a cumbersome mechanism for defining terminal illness, we could seek to very clearly but arbitrarily define terminal illness, for example by restricting access to patients whose

\footnotetext{
21 Ibid.

22 'Informed consent: lessons from Australia' Loane Skene and Richard Smallwood. British Medical Journal 2002, v. 324 (7328), p. 39.
} 
prognosis, according to their medical doctors, is less than 12 months. But again we run into problems. What if, by nature of their illness, a patient will not be capable of consenting during their final 12 months due to the nature of the illness' progression? Wouldn't we be tacitly accepting an unjust system due to the inevitable variance of professional medical opinion with respect to a patient's prognosis - couldn't identical patients with different medical teams be offered access to euthanasia at different times due to these professional differences of opinion? And what makes 12 months the right amount of time? Why not six or three or 36 ? In total, the answers to these questions cannot be satisfactorily provided without recognition of the underlying unfairness inherent in an arbitrary medical definition. (Such a problem reoccurs in the exclusion of children from euthanasia access, as I will discuss later.) The pragmatic advantage of such a definition, however, is that cases can be readily measured against it. Should this advantage of the definition prove to outweigh its potential arbitrary unfairness, then we could seek to adopt it in legislation. However, if this advantage does not seem to outweigh the potential for arbitrary unfairness (as I think it does not), and we still wish to restrict euthanasia access to those commonly conceived as being terminally ill, then we are left with two options: we may return to the standard of what a reasonable patient would consider unacceptable treatment while accepting that there can be no perfectly consistent judgement of what is reasonable - perhaps so much so that differences in professional legal opinion would result in the same injustices as would occur in the arbitrary medical definition; or, we could leave this determination predominantly up to the patients and doctors involved in each case (as the Territory's Act seemed to do).

Alternatively still, we could altogether abandon the requirement of the patient's illness being terminal. After all, couldn't a patient who is not terminally ill conceivably be suffering just as much as someone who is? In a physical or emotional sense, this is easily imagined. However, the sense that might intuitively be thought of as different is the existential one. Surely one could not suffer existentially without one's existence being physically threatened. But what about non-physically threatened? Although we could draw this up to another definitional issue, we cannot ignore there 
being some common themes when people come to defining existential suffering ${ }^{23}$. The definitions given by chaplains, palliative physicians, and algologists (physicians specialising in the treatment of pain) typically emphasise different words and concepts. Yet, among these differences ${ }^{24}$, there remain common themes, like anxiety of the future, the meaning of one's life, and personal relationships. Such themes can and have reoccurred in the thoughts of relatively physically and emotionally healthy people (or, at least, not people without terminal illness), like in the Dutch case of Edward Brongersma ${ }^{25}$. The former Dutch senator was euthanised by his general practitioner in 1998 after repeated requests and claiming he was 'weary of life'. His doctor testified that Brongersma felt personally important parts of his life's work (and, therefore, his life's meaning) as a political activist had not succeeded in the way he had hoped, and that, combined with the deaths of his close friends and his own declining health, he had become weary of life. The GP made no intimation that Brongersma felt he had become weary of being a burden on society due to his age, as is sometimes ${ }^{26}$ argued as being a prominent concern due to the commonly negative view society has of the aged generally ${ }^{27}$. Such a case should therefore be defined in terms of existential suffering. Brongersma's meaning in life and personal relationships were being taken away from him, and he was likely under no disillusionment that he, like his remaining friends, would die soon, too (he had

\footnotetext{
23 'Existential Pain - An Entity, a Provocation, or a Challenge?' Peter Strang, Susan Strang, Ragnar Hultborn, and Staffan Arnér. Journal of Pain and Symptom Management 27; No. 3 p. 248.

${ }^{24}$ Ibid 8.

${ }^{25}$ Sutorius/Brongersma, Nederlandse Jurisprudentie 2003, no. 167.

26 'Assistance in dying for older people without a serious medical condition who have a wish to die: a national cross-sectional survey' Natasja Raijmakers, Agnes van der Heide, Pauline Kouwenhoven, Ghislaine van Thiel, Johannes van Delden, Judith Rietjens. Journal of Medical Ethics, 2013, doi:10.1136/medethics-2012-101304, p. 1.

27 'Retrospective analysis of attitudes to ageing in the Economist: apocalyptic demography for opinion formers' Ruth Martin, Caroline Williams, Desmond O'Neill. British Medical Journal, 2009, v. 339 (7786), p. 1435.
} 
potential to be anxious about his future). Could he have found meaning for his life in something new? Could he have overcome his anxiousness about the future, and created new interpersonal relationships? Perhaps. However it is a big ask of someone to effectively recreate the most meaningful and intimate parts of their life. Some might not even feel their 'new' life was their own that their real life was their old one, the one they lost, and phoney replacement wouldn't make 'them' whole. Said differently, once they lost their original meaning, in a sense they were already dead. It's no wonder that, after facing tragic personal loss like the death or deaths of loved ones, people often describe themselves as feeling 'lost' or 'like a ghost'. In these cases, their identities had been invested in these relationships or what or who they lost. And with the loss of these people or things, their identity is lost, and so it is quite literally true that they themselves are lost, in that moment - they, the person (as they were), no longer exist ${ }^{28}$. As anthropologist Margaret Lock describes of how individuals are conceived in traditional Japanese culture, "individuals ... are conceptualized as residing at the center of a network of obligations, so that personhood is constructed out-of-mind, beyond body, in the space of ongoing human relationships." ${ }^{129}$ When we lose our relationships or obligations we have to ourselves or others that instil us with meaning, our personhood diminishes. It is at these often dire moments that we are left with a choice: will we resurrect our persons anew, will we choose to live with this sub-personhood, or will we choose to let get of our personhood altogether? Clearly it is not rational nor preferable for us to make a decision of life or death in what can be only be an emotionally-orientated state of mind, given the circumstances and our human nature. However, if, after pushing through this initial emotional stage, we come to a rational decision about how we would prefer our life to proceed, there seems to be no obvious justification for society to impose the opposite of whatever we prefer. That is, barring

\footnotetext{
28 'Life's Dominion: An Argument About Abortion, Euthanasia, and Individual Freedom' Ronald Dworkin, 1993, Alfred A. Knopf, p. 211.

29 'Contesting the Natural in Japan: Moral Dilemmas and Technologies of Dying' Margaret Lock. Culture, Medicine, and Psychiatry, 1995, v. 19, p. 22.
} 
exceptional cases where you had a serious obligation to society or part thereof - even if it were only to a single individual. For example, we might say that non-life sentenced prisoners or life-sentenced prisoners with the possibility of parole have an obligation to society to attempt rehabilitation. A lifesentenced prisoner without the possibility of parole does not have this obligation due to the purpose of their imprisonment being to effect their permanent removal from general society for theirs and society's own good; their only remaining obligations are to themselves and possibly to their victims or some higher institution of justice (perhaps, too, to their friends or family, but we should not attempt to legislate interpersonal ethics to this degree).

Walt Kowalski, the protagonist of the film Gran Torino (2008), is a classic redemption or 'personal resurrection' story. He valued his family, especially his wife, but when she died and Walt couldn't connect with his children, horrors he had witnessed in the Korean War plagued his thoughts and he felt his life lacked any positive meaning. In a very literal sense, his life (as he had once known it) was over, and all that remained was negative emotions and memories. In a scene where Walt's priest challenges him to explain what he knows about life and death, Walt readily recounts his nightmares from Korea, but when asked "What about life?", he can merely offer elementary autobiographical, not vivid nor emotive, details. At this point, Walt had a choice: he could seek to physically die, he could physically live but remain existentially dead, or he could attempt to work a 'miracle' by resurrecting the existential (or whole) part of his person (that is, discovering or creating new meaning for his life). In the film, circumstances would oblige him to create new meaning in the form of protecting and informally adopting his neighbours' children, who were being targeted by a local gang. In this way, he becomes like the prisoner who has an obligation to society, only this obligation wasn't entirely self-imposed, but rather more due to happenstance. He accepts this obligation begrudgingly, at first, perhaps because he feels that by replacing the old meaning of his family with a new meaning would be to totally let go of the old one, however painful and bereft it remains. Such evolution of life's meaning might not be possible or preferable for all. Had it not been for exceptional circumstances, Walt may never have made such a transition. If he had not been 
obliged (or forced by circumstance) and had instead been posed with the free choice of whether to recreate the existential part of his person, whatever conscious choice he made (due to whatever reasons he chose, so long as they had been rationally-based) should have been respected.

Had he decided against transformation, as Brongersma did, we could not fault him (again, so long as he made this choice rationally and did not rely purely on his emotions). He - like Brongersma - faced a reduced level of personhood via existential death brought about by extreme and prolonged existential suffering. He would have merely been aligning his physical and emotional self with his existential self. In Brongersma's case, this was not seen as valid cause for medical assistance in dying. 'Unbearable suffering', as is required in the Netherlands to be eligible for euthanasia, was decided by the Supreme Court via this case as having a limited meaning: the suffering could only be that which was explained by disease, and excludes 'non-medical' (existential) suffering. This, however, overmedicalises and -technifies the role of the medical profession, which is primarily to heal. To discriminate between types of suffering based on their source or form (rather than, say, their severity), is fundamentally inconsistent with the medical profession's primary role of healing. Yes, the medical profession may be ill-equipped and even claim to have "no expertise to judge such suffering" ${ }^{130}$, but this does not mean they do not have a role in treating such suffering if it can be independently judged by the person or by other professions who do have the expertise to judge such suffering. Further, it should be the obligation of the medical profession to seek expertise in the judgement of such suffering so that they may fulfil their role as healers. Failing to do so is to unfairly discriminate against those who just so happen to suffer from the 'wrong' source. Historically, this happened a large scale once before; for a time, some in the medical profession did not recognise (and some still do not fully recognise) the types of psychological suffering experienced by those with mental disorders. They might say something like, "Because I can't see this in a blood test or an x-ray,

\footnotetext{
30 '"Existential" suffering not a justification for euthanasia' Tony Sheldon. British Medical Journal 2001 323; p. 1384.
} 
it doesn't exist or it can't be treated via medical means." Although we now know that many mental disorders have biological bases, we also recognise that such disorders can be generated in part or whole by a person's experience - post-traumatic stress disorder, for example. Yet, despite such conditions being induced psychosocially (or not having a strictly biological aetiology in the first instance), we still endeavour to treat the resultant suffering medically because we recognise that such suffering both exists, and can be alleviated via medical means. The same is also true for existential suffering.

Ideally, if someone is competent and rational, we ought to allow that person to determine what their own level and severity of suffering is as a direct result of their experiencing it (incidentally, we routinely employ such a system in triage situations for grading physical suffering by asking, "On a scale of one to ten, with ten being the worst pain possible [or, sometimes, 'ever experienced'] and one being no pain, how much pain are you in?"). Attempts to ignore 'non-medical' suffering by evoking a suffering value system where source is what matters is fundamentally misaligned with medicine's role to heal and goes against medical practice's otherwise near-total respect for autonomy (in this case, the autonomy to choose our own value system for whether the source of suffering matters). Even if some medical doctors cannot, at this moment, fathom that existential suffering exists or should be treated medically, it does not justify their enforcement of their own values upon patients. As Kymlicka wrote ${ }^{31}$ : "While we may be mistaken in our beliefs about value, it doesn't follow that someone else, who has reason to believe that a mistake has been made, can come along and improve my life by leading it for me, in accordance with the correct account of value. On the contrary, no life goes better by being led from the outside according to values the person doesn't endorse. My life only goes better if I'm leading it from inside, according to my beliefs about value."

\footnotetext{
31 'Liberalism, Community and Culture' Will Kymlicka. Clarendon Press, 1989, p. 12.
} 
The only bastion of refuge might be that, if someone is onl experiencing existential suffering and not physical or emotional suffering, and otherwise has the autonomy and ability to commit unassisted suicide, then perhaps medical doctors should focus their efforts on helping those who could otherwise not physically or emotionally commit unassisted suicide. However, such a justification could only be invoked in situations where the number of patients who were requesting euthanasia far outnumbered the means of carrying out their euthanasia. This is similar to how we might justify making a patient change their own bandage if they were physically able to in an overcrowded hospital which had limited medical staff. Were the hospital not overcrowded and understaffed, then such a justification would not be possible.

\section{Age requirements}

A slightly different form of unjust discrimination in Australian proposals to legalise euthanasia has been age restrictions, except that it involves one added complication: informed consent. Although no provisions for children to access euthanasia have made their way into any proposed legislation in Australia, this deficiency has been raised during parliamentary debate and was even raised during the very first debate, in 1995: "This proposed legislation provides that something can be done provided the person is over 18 [years of age]. However, if it were my 9-year-old stepdaughter who happened to be in that circumstance, it would be okay for me to watch her continue to suffer. The legislation has no provision for children. Is it easier to watch a child dying in agony than an adult? ... Will we deal with children? What happens when a [child with Down's syndrome] is dying in agony. Do we ignore them too? Why is it right for a mentally-competent adult, but not right for anybody else? ... Interestingly, a 17-year-old cannot make a choice [to be euthanised], but an 18-year-old can..$^{132}$

\footnotetext{
${ }^{32}$ Northern Territory Seventh Assembly First Session 23 May 1995 Parliamentary Record No. 11 p. 3622-3.
} 
In 2012, there were 147,098 deaths in Australia. Of those, 2,003, or 1.36 per cent, were of people aged 19 years or younger ${ }^{33}$. Since not all of these deaths would have been slow or involved unbearable suffering, it is fair to say there would be very few cases where euthanasia for children could be a conceivable option in comparison to adult cases (whatever the exact numbers). That does make this a minor issue, however - the unnecessary suffering of children should still be avoided if possible and if those children wish to avoid it. We might even have more reason to avoid such suffering than we do in the case of adult suffering, since we typically view such early deaths and suffering as particularly unfair and heartbreaking ${ }^{34}$; "They weren't given the opportunity live a full, or even close to full, life," or "Their overriding experience of life has been suffering and illness."

As implied during parliamentary debate, restricting access to euthanasia to those aged 18 years and over relies on an arbitrary judgement of what constitutes an individual who has the capacity to consent to something. While such arbitrary judgements might make the application of laws more straightforward (like they do when using a medically arbitrary definition of terminal illness), unjust consequences inherently follow. A 17-year-and-364-day-old child does not become, overnight, a fully-competent adult, capable of consenting to euthanasia; autonomy and the competency to make one's own decisions is a gradual process, and we should recognise it as such. This is also part of accepted parenting practices. We probably would not think it was appropriate for a parent to let their 4-year-old child travel independently to school, whereas when the same child is 14-years-old we wouldn't have the same concerns. Likewise, if a child does not understand the concepts of life and death, we could not find it appropriate for that child to be given the choice to be euthanised, however if they did, and could demonstrate this understanding to us, how could we still find their being given this choice inappropriate?

\footnotetext{
33 '3302.0 - Deaths, Australia, 2012' Australian Bureau of Statistics. Released 7 November 2013.

34 'Rethinking Life and Death: The Collapse of Our Traditional Ethics' Peter Singer. St Martin's Press, 1996, p. 213.
} 
It could be that we would still have intuitive biases and doubts about whether a child can or really does understand the ramifications of their decision, and this could be clouding our rational judgement of their capacities and maturity. We also tend to look upon children as uniformly innocent, naïve, and therefore in need of our protection. Empirically, however, not all may need as much protection as we might think; by the age of seven most children have a good understanding of what death is ${ }^{35}$. This involves understanding a number of features of death ${ }^{36}$, namely universality (that we all die), irreversibility (that once we are dead we cannot become alive again), nonfunctionality (that we cease to function as humans upon death), and causality (that disease, accident, or other internal and external events can lead to death). However, advanced understanding of death is unlikely to come all at once, and probably involves a gradual development of understanding, starting at the level of individual features. For example, a child might be aware of the universality of death but simultaneously have unrealistic beliefs about causality ${ }^{37}$. Although more empirical research needs to be conducted on this topic, there have been some reports of terminal illness and the experience of the death of a loved one impacting positively on children's conceptions of death ${ }^{38}$ - that is, their conception became more realistic or they understood certain features of death better than children without these experiences. This is understandable given that in a hospital context (as terminally ill children or children who have experienced the loss of a loved one will be familiar with), they are exposed to a fundamentally different environment to that which they have otherwise experienced or that a normal child would experience. In a hospital setting, you

\footnotetext{
35 'Children's Concepts of Death' Mark Speece. Michigan Family Review, 1995, v. 1, p. 68.

${ }^{36}$ Ibid. p. 57.

37 'Differences in Death Concepts Between Children With Cancer and Physically Healthy Children' Susan Jay, Vicki Green, Sharon Johnson, Steven Caldwell, Rupert Nitschke. Journal of Clinical Child Psychology, 1987, v. 16 (4), p. 305.

${ }^{38}$ Ibid.
} 
are surrounded by the realities of death, and may even become aware of age peers who are dying, suffering, or have died.

Still, we might have reason to suspect that a child who does not yet understand death but could - if they did understand it - benefit from being given the option to be euthanised. In this case, we should not present the option to the child until we first can help them to come to an understanding about their current situation and can also form a realistic conception of death. Parents and carers inform children of the child's medical condition and treatment options, helping them to form accurate conceptions of what life would be like, for example, after undergoing a particular surgery. In the same way, parents and carers could help children form accurate conceptions of what it would be like if the child died (where that is likely, such as due to the natural progress of a terminal illness, or where that might be preferable to the child if they are experiencing severe suffering). That they merely do not yet understand it due to their passively gained knowledge of death via their experience of the world does not necessarily mean they are incapable of understanding death if it was actively explained to them. And, in some cases, such active explanation may be as warranted as other types of explanation about the likely progression of a disease or the amount of suffering the child is likely to experience in the future due to that disease.

\section{Conclusions}

Ultimately, someone's age or the source of their suffering should not be barriers to euthanasia access. Having an accurate conception of death and basing one's decision on rational beliefs, however, are justifiable barriers to euthanasia access. Restricting access to terminally ill adults arbitrarily deprives non-terminally-ill and/or non-adults from salving their unnecessary suffering. An objection to this might be that such arbitrariness is juridically required if any laws to legalise euthanasia are to be practicable. While in other contexts we might be able to acknowledge that some children would be capable (being adequately mature and responsible) of driving a car or being able to independently sign a contract, having an arbitrary line in the sand is merely an inconvenience 
and not a matter of life, death, or unbearable suffering. The level of injustice we accept in disallowing mature and responsible children from being able to independently drive a car is not the same level of injustice as we would be accepting if we disallowed mature and responsible children from accessing euthanasia when they were experiencing unbearable and extreme suffering (additionally assuming they had accurate conceptions of death and would base their decision on rational beliefs). Given this hugely disparate level of injustice in accepting one case of arbitrariness compared to the other, we can say that in different cases we can be better justified in using an somewhat arbitrary standard than in others.

As for the many Australian proposals which attempted to (or successfully) legalise(d) euthanasia, none were singularly perfect. None, for example, allowed children to access euthanasia, and few sought to allow non-terminally-ill patients access. Proposals which had a breadth of oversight and broad eligibility conditions were therefore best, and should have generally been passed. One of the best exemplars among the proposals was the Dignity in Dying Bill 2005, presented by Bob Such in the South Australian House of Assembly. It did not completely discriminate against non-terminally-ill patients, however, the definition used would still not cover existential suffering alone due the requirement that the suffering be a result of an "injury or illness" ${ }^{139}$. As well as discriminating against the source of suffering, it (like all other proposals) unfairly discriminated against the suffering experienced by children. Nonetheless, like many other proposals, it would have been a step in the right direction, and we cannot reasonably expect perfect legislation to pass all at the same time or within a single bill - there will likely be a gradual advance in ethical thinking, like we have observed over the past 20 years. Ideally, though, Australian - and international - proposals ought to incorporate more sophisticated and realistic views of autonomy, capacity for understanding, and suffering. We should seek to establish the role of the medical profession as indiscriminate healers of human suffering - whatever the source is, and whatever age the person experiencing it is.

\footnotetext{
${ }^{39}$ Dignity in Dying Bill 2005. South Australian House of Assembly No. 79. p. 3.
} 


\begin{tabular}{|c|c|c|c|}
\hline \multicolumn{4}{|c|}{$\begin{array}{l}\text { Appendix I. List of proposed } \\
\text { parliament in Australia. }\end{array}$} \\
\hline Year & Parliament & Presented by & Proposed bill title (and number) \\
\hline 1995 & NT & MP & Rights of the Terminally III Bill (Serial 67) \\
\hline 1995 & SA & $J Q$ & Voluntary Euthanasia Bill \\
\hline 1995 & ACT & MM & Medical Treatment (Amendment) Bill \\
\hline 1996 & SA & $\mathrm{AL}$ & Voluntary Euthanasia Bill \\
\hline 1997 & WA & NK & Voluntary Euthanasia Bill (87) \\
\hline 1997 & ACT & MM & Euthanasia Referendum Bill \\
\hline 1998 & WA & NK & Voluntary Euthanasia Bill (8) \\
\hline 2000 & SA & BS & Dignity in Dying Bill \\
\hline 2000 & WA & NK & Voluntary Euthanasia Bill (121) \\
\hline 2001 & NSW & IC & Rights of the Terminally III Bill \\
\hline 2002 & SA & BS & Dignity in Dying Bill \\
\hline 2002 & WA & $\mathrm{RC}$ & Voluntary Euthanasia Bill (149) \\
\hline 2002 & SA & SK & Dignity in Dying Bill \\
\hline 2003 & NSW & IC & Voluntary Euthanasia Trial (Referendum) Bill (?) \\
\hline 2005 & SA & BS & Dignity in Dying Bill (79) \\
\hline $2006-8$ & SA & BS & Voluntary Euthanasia Bill (2006/102), (2007/14), (2008/20) \\
\hline 2008 & SA & MP & $\begin{array}{l}\text { Consent to Medical Treatment and Palliative Care (Voluntary } \\
\text { Euthanasia) Amendment Bill (34) }\end{array}$ \\
\hline 2008 & VIC & $\mathrm{CH}$ & Medical Treatment (Physician Assisted Dying) Bill \\
\hline 2009 & TAS & NJM & Dying with Dignity Bill (37) \\
\hline 2010 & SA & BS & Voluntary Euthanasia Bill \\
\hline 2010 & SA & MP & Consent to Medical Treatment and Palliative Care (Voluntary \\
\hline
\end{tabular}




\begin{tabular}{|l|l|l|l|}
\hline & & & Euthanasia) Amendment Bill \\
\hline 2010 & SA & SK & Criminal Law Consolidation (Medical Defences-End of Life \\
\hline 2010 & WA & RC & Voluntary Euthanasia Bill (108) \\
\hline 2011 & SA & SK & Criminal Law Consolidation (Medical Defences-End of Life \\
\hline 2012 & SA & BS & Arrangements) Amendment Bill (88) \\
\hline 2013 & NSW & CF & Rights of the Terminally Ill Bill \\
\hline 2013 & TAS & LTG \& NJM & Voluntary Assisted Dying Bill (61) \\
\hline 2013 & SA & BS & Ending Life with Dignity Bill (213) \\
\hline 2014 & Cmth & RD & Medical Services (Dying with Dignity) Exposure Draft Bill \\
\hline
\end{tabular}

Five additional bills proposed in the federal senate attempted to repeal the Euthanasia Laws Act 1997, which was used to overrule the Northern Territory's 1995 decision to enact the Voluntary Euthanasia Bill. The federal bills to undo the overruling were excluded from the above list as they did not propose new laws and would otherwise have an identical ethical assessment as the Northern Territory's 1995 legalisation bill. For reference, however, these bills were titled: Euthanasia Laws (Repeal) Bill 2004; Australian Territories Rights of the Terminally III Bill 2007; Rights of the Terminally III (Euthanasia Laws Repeal) Bill 2008; Restoring Territory Rights (Voluntary Euthanasia Legislation) Bill 2008; Restoring Territory Rights (Voluntary Euthanasia Legislation) Bill 2012.

"Due to South Australian parliamentary procedure and the sitting program for the $51^{\text {st }}$ Parliament of South Australia, BS was required to re-present his 2006 bill (no. 102) to the second and third sessions of parliament in 2007 (no. 14) and 2008 (no. 20), respectively. The bills are identical.

${ }^{* *}$ RD's 2014 bill is not yet a formally presented bill, but is likely to be soon, and thus included in this 


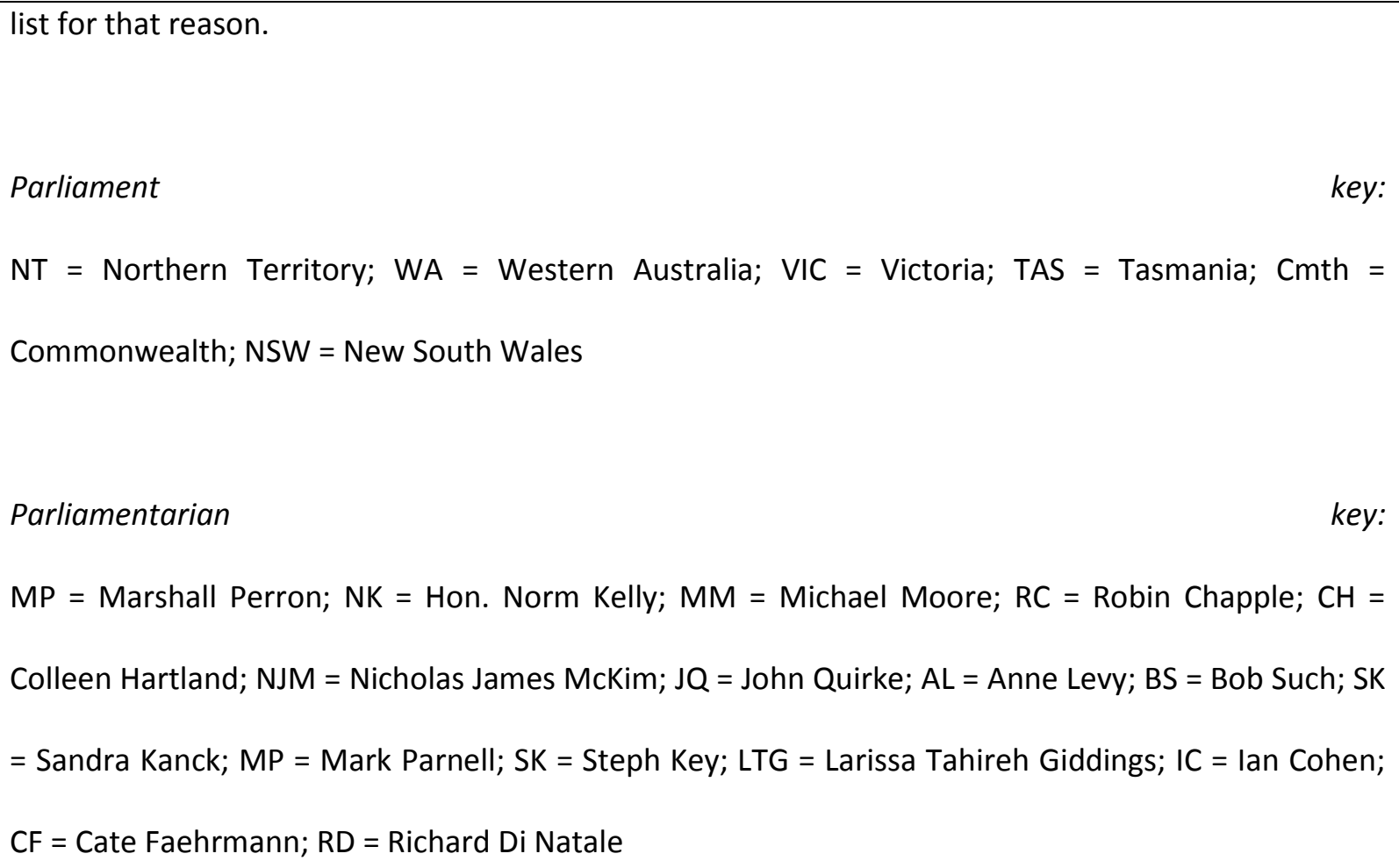

